\title{
A 3 Year Old Case of Juvenile Mitral Stenosis- the Youngest Case Reported
}

\author{
Ranjan Modii ${ }^{*}$, SV Patted ${ }^{2}$, Prabhu Halkati², MD Dixit ${ }^{2}$ and Veeresh Manvi \\ ${ }^{1}$ Fortis Escorts Heart Institute, India
}

${ }^{2}$ KLE Hospital and MRC, JN Medical College, India

Submission: May 05, 2017; Published: June 29, 2017

*Corresponding author: Ranjan Modi, Fortis Escorts Heart Institute, Okhla, New Delhi, India, Tel: 09844917110; Email: Ranjan_Modi@Hotmail.Com

Abstract

Rheumatic heart disease is a well-known entity in the developing world. The commonest sequelae of rheumatic carditis are mitral stenosis (MS). MS can present at a very young age with severe symptoms. We describe here a case of juvenile rheumatic MS in a 3 year old child with severe pulmonary hypertension.

\section{Background}

Rheumatic fever and rheumatic heart disease (RHD) continues to be a significant cause of morbidity and mortality in developing countries including India. It constitutes the most common form of valvular heart disease in India. The reported prevalence of RHD is 1.0 to 5.4 per 1,000 school children in our country [1]. Rheumatic mitral stenosis (MS) is a common problem in young children and adolescents and it can often lead to severe symptoms [2]. MS is a condition characterized by structural abnormality of the mitral valve apparatus that results in obstruction to left ventricular inflow. The most common cause of MS is rheumatic carditis. Other causes are extremely uncommon and include congenital MS, mitral annular calcification (MAC), carcinoid syndrome, mucopolysaccharidosis, Fabry's disease, Whipple's disease, amyloidosis and methysergide therapy [1].

Recurrent and severe episodes of rheumatic fever can lead to early development of RHD that may be confused with congenital causes of mitral valve disease in the young population. RHD follows rheumatic fever (RF), as a non-suppurative manifestation of group A beta haemolytic streptococcal (GAS) pharyngitis. RF is widely accepted as an immunological disorder following GAS infection. Rheumatic valvulitis most commonly affects the mitral valve $(70 \%$ to $75 \%)$ followed by combined mitral and aortic involvement (20\% to $25 \%)[1,2]$.

\section{Case Report}

Our patient a 3 year old boy, weighing $9 \mathrm{Kgs}$, with a history of recurrent cough with expectoration since last one year presented with recent worsening of dyspnoea associated with paroxysmal nocturnal dyspnea. His medical history did not have any history suggestive of rheumatic fever. On examination patient was dyspneic at rest with marked tachycardia. The precordial examination revealed precordial buldge, parasternal and epigastic pulsations, loud S1, parasternal Heave with palpable and loud P2, with a long Mid-diastolic murmur with pre systolic attenuation at the apex.

The electrocardiogram (ECG) showed sinus tachycardia with rightaxis deviation $\left(+110^{\circ}\right)$, left atrial enlargement and right ventricular hypertrophy (RVH) (Figure 1). The chest x-ray showed evidence of left atrial enlargement, pulmonary venous hypertension and pulmonary arterial hypertension (Figure 2). The two-dimensional transthoracic echocardiogram (TTE) revealed thickening and shortening of the anterior and posterior mitral leaflets and chordae, fusion of the commissures with anterior leaflet doming and fixed posterior mitral leaflet (Figure 3 ), turbulent mitral inflow jet, severe subvalvular stenosis with peak pressure gradient of $27 \mathrm{mmHg}$, mean pressure gradient of $19 \mathrm{mmHg}$ and mitral valve opening of $0.35 \mathrm{~cm} 2$ by planimetry (Figure 4). The patient also had severe tricuspid regurgitation with peak gradient of $76 \mathrm{mmHg}$ (Figure 5) and severe pulmonary hypertension, estimated right ventricular systolic pressure $91 \mathrm{mmHg}$. With all these echocardiographic evidences and clinical condition of congestive cardiac failure, a diagnosis of severe MS and severe pulmonary artery hypertension (PAH) was concluded. The patient clinical condition was initially stabilized 
by strict bed rest and decongestive therapy with diuretics. After intial stabilization the patient was taken for commissurotomy.
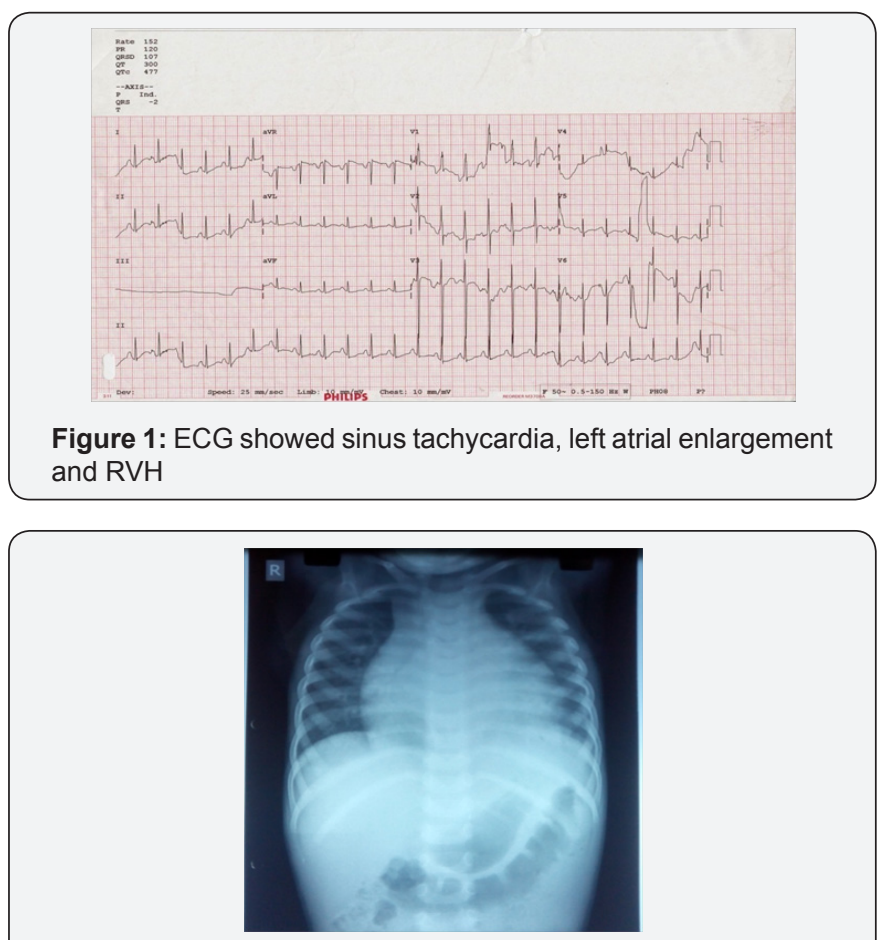

Figure 2: Evidence of left atrial enlargement, pulmonary venous hypertension and pulmonary arterial hypertension.
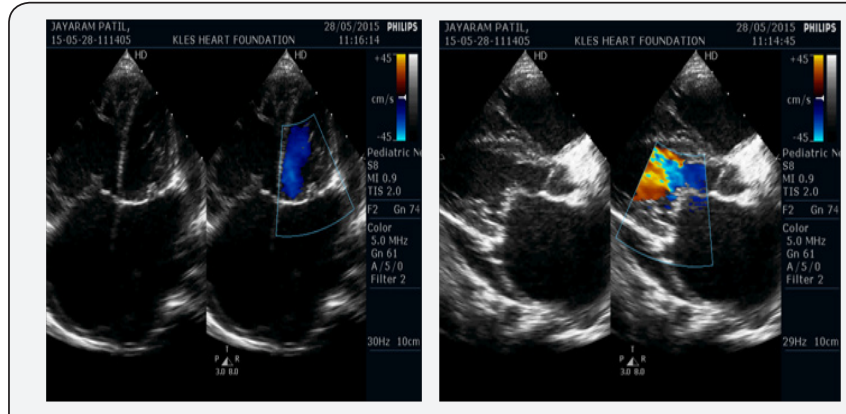

Figure 3: Two-dimensional transthoracic echocardiogram revealed thickening and shortening of the anterior and posterior mitral leaflets and chordae, fusion of the commissures with anterior leaflet doming and fixed posterior mitral leaflet.
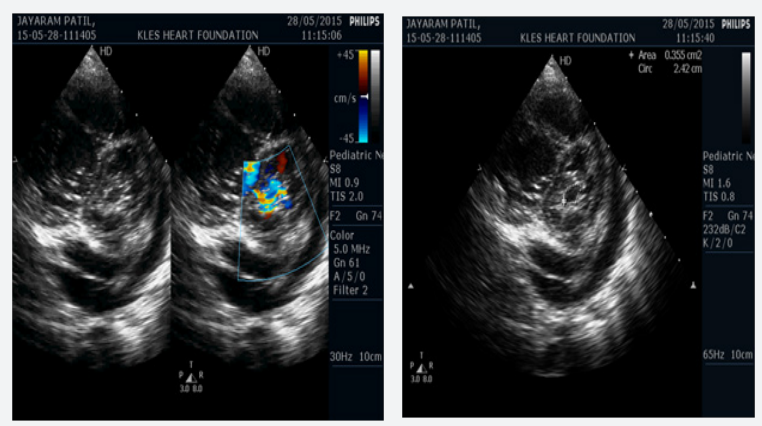

Figure 4: Two-dimensional transthoracic echocardiogram revealed severe subvalvular stenosis and mitral valve opening of $0.35 \mathrm{~cm} 2$ by planimetry

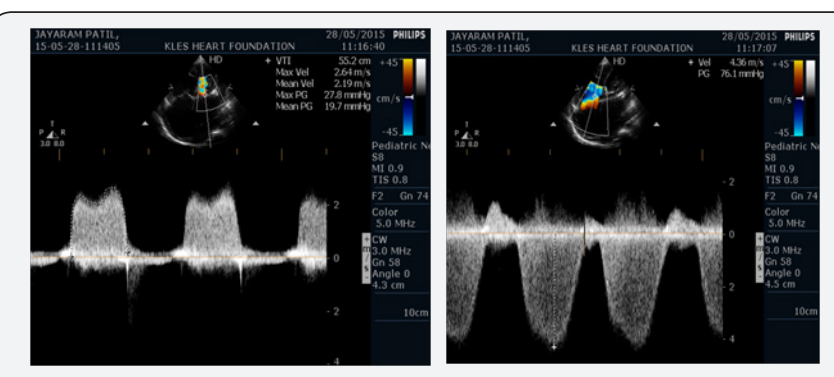

Figure 5: Two-dimensional transthoracic echocardiogram peak pressure gradient of $27 \mathrm{mmHg}$, mean pressure gradient of $19 \mathrm{mmHg}$ and severe tricuspid regurgitation with peak gradient of $76 \mathrm{mmHg}$.

The patient was taken for commissurotomy followed by mitral valve repair. During operative repair inspection revealed pericardial inflammation with thickened, scarred, severe commissural and subvalvular fusion, which were suggestive of RHD. Commissurotomy was done with annuloplasty using $18 \mathrm{~mm}$ Goretex Ring. Mitral valve replacement was done using $18 \mathrm{~mm}$ Medtronic aortic valve in inverted position. Post operatively the patient was not doing well and expired after 3 days of surgery.

\section{Discussion}

In most of the developed countries the prevalence of rheumatic fever has declined in past decades, but in the developing countries like India, the disease is still prevalent. Isolated severe rheumatic mitral stenosis in children and young adults is frequently encountered up to $25 \%$ of patients. The term Juvenile mitral stenosis (JMS) stands for patients younger than 20 years of age [3].

JMS is characterized by severe stenosis of the mitral valve, a high prevalence of severe PAH and pulmonary venous hypertension, less often has Atrial Fibrillation and Left Atrium Dilatation [4]. Severe subvalvular pathology is almost universally extensive and is grade 3 or 4 in most of these patients [5]. Severe $\mathrm{PAH}$ is seen in over one-third of these patients. Recurrence of RF is more common in these patients, given their age. Balloon Mitral Valvotomy, closed surgical commissurotomy and Mitral Valve surgery are approaches available for this subgroup of patient of Juvenile Mitral Stenosis [6,7].

Recurrence of RF is more common in these patients, given their age. The results of percutaneous transluminal mitral commissurotomy (PTMC) are similar to those in adults [8], though the incidence of restenosis may be higher, especially in those who have active disease at the time of the intervention [9]. Mitral valve surgery carries the risk of acute complications, and children and adolescents may require reoperation 10 to 15 years later.

Many articles in the past have defined Juvenile MS suggesting that the age of presentation of these individuals has been decreased with each passing year. This advancement in detection of these patients is attributable to improvement in the 
imaging techniques of echocardiography, improved knowledge of the clinician and intuition regarding this entity.

Our patient was aged only 3 years at the time of presentation with Juvenile Mitral Stenosis which is very unusual. The presentation of any patient at such a young age has been not previously documented in literature.

\section{References}

1. Manjunath CN. Valvular heart disease. API Text book of medicine $9^{\text {th }}$ edition.

2. (2004) Rheumatic fever and rheumatic heart disease. World Health Organ Tech Rep Ser 923: 1-122.

3. Shrivastava S, Tandon R (1991) Severity of rheumatic mitral stenosis in children. Int J Cardiol 30(2): 163-167.

4. Roy SB, Bhatia ML, Lazaro EJ, Ramalingaswami V (1963) Juvenile mitral stenosis in India. Lancet 2(7319): 1193-1195.
5. Wilkins GT, Weyman AE, Abascal VM, Block PC, Palacios I (1988) Percutaneous balloon dilatation of the mitral valve: An analysis of echocardiographic variables related to outcome and the mechanism of dilatation. Br Heart J 60(4): 299-308.

6. Bahl VK, Chandra S, Kothari SS, Talwar KK, Sharma S, et al. (1994) Percutaneous transvenous mitral commissurotomy using Inoue catheter in juvenile rheumatic mitral stenosis. Cathet Cardiovasc Diagn Suppl 2: 82-86.

7. Harikrishnan S, Nair K, THarakan JM, Titus T, Kumar VK, et al. (2006) Percutaneous transmitral commissurotomy in juvenile mitral stenosiscomparison of long term results of Inoue balloon technique and metallic commissurotomy. Catheter Cardiovasc Interv 67(3): 453-459.

8. Kothari SS, Kamath P, Juneja R, Bahl VK, Airan B (1998) Percutaneous transvenous mitral commissurotomy using Inoue balloon in children less than 12 years. Cathet Cardiovasc Diagn 43(4): 408-411.

9. Kothari SS, Ramakrishnan S, Juneja R, Yadav R (2006) Percutaneous transvenous mitral commissurotomy in patients with severe mitral stenosis and acute rheumatic fever. Pediatr Cardiol 27(3): 347-350.

\section{Your next submission with Juniper Publishers} will reach you the below assets

- Quality Editorial service

- Swift Peer Review

- Reprints availability

- E-prints Service

- Manuscript Podcast for convenient understanding

- Global attainment for your research

- Manuscript accessibility in different formats ( Pdf, E-pub, Full Text, Audio)

- Unceasing customer service

Track the below URL for one-step submission https://juniperpublishers.com/online-submission.php 